\title{
Anatomia das plântulas de Mimosa pilulifera (Leguminosae) CRESCENDO EM SOLO CONTAMINADO COM PETRÓLEO E SOLO BIORREMEDIADO
}

\author{
Renata Charvet Inckot ${ }^{1}$, Cleusa Bona ${ }^{1,3}$, \\ Luiz Antonio de Souza ${ }^{2} \&$ Gedir de Oliveira Santos ${ }^{1}$
}

\begin{abstract}
RESUMO
(Anatomia das plântulas de Mimosa pilulifera (Leguminosae) crescendo em solo contaminado com petróleo e solo biorremediado) A demanda de petróleo e derivados provoca acidentes que contaminam extensas áreas. A maioria dos trabalhos sobre os efeitos dessa contaminação refere-se à germinação e desenvolvimento vegetal, pouco se sabendo sobre os efeitos na estrutura de tecidos e células. Este trabalho teve como objetivo analisar o efeito do solo contaminado por petróleo e solo biorremediado na anatomia de plântulas de Mimosa pilulifera (Leguminosae). O experimento foi realizado com solo da REPAR/PETROBRÁS, Araucária-PR, onde ocorreu um vazamento de petróleo em 2000. O experimento constou de três tratamentos: solo contaminado com petróleo, solo biorremediado e solo não contaminado, com cinco repetições. Após 30 dias da semeadura, foram analisados anatomicamente a raiz, hipocótilo, cotilédone e eofilo e realizados testes microquímicos com sudan III, lugol e cloreto férrico. Mensuraram-se: diâmetro do cilindro vascular e espessura do córtex da raiz, diâmetro do hipocótilo e espessura dos cotilédones e eofilos. A estrutura celular radicial de $M$. pilulifera sofreu maior interferência no solo contaminado que no biorremediado. Na parte aérea, a única alteração foi a redução da espessura do eofilo em solo contaminado. Palavras-chave: raiz, hipocótilo, cotilédone, eofilo, hidrocarbonetos.
\end{abstract}

\begin{abstract}
(Anatomy of the Mimosa pilulifera (Leguminosae) seedling growing in petroleum contaminated and bioremediated soil) The demand of oil and its derivatives have provoked accidents, contaminating areas of the planet. The majority of are relative to the effect in seed germination and plant development. Little is known on the effect of the hydrocarbons in the structure of the tissues and plant cells. This work intends to analyse the effect of the ground contaminated by oil and the bioremediated ground on the anatomy of seedlings of Mimosa pilulifera. The experiment was carried through with ground proceeding of the REPAR/PETROBRÁS, Araucária-PR, where a leak of oil occurred in 2000. The experiment consisted of three treatments: petroleum contaminated soil, bioremediated soil and non contaminated soil, with five repetitions. Thirty days after sowing, 10 seedlings were collected per treatment. The root, the hipocotyl, the cotyledon and the eophyll were analysed anatomically and were submitted to histochemical tests with Sudan III, lugol and ferric chloride. The diameter of the vascular cylinder and the thickness of the cortex of the root, the diameter of the hipocotyl and the thickness of the cotyledons and eophylls were measured. The cellular structure of the root of $M$. pilulifera suffered greater interference in the contaminated soil that the biorremediated. In shoots, the only change was the reduction in the thickness of eophyll in contaminated soil.
\end{abstract}

Key words: root, hipocotyl, cotyledon, eophyll, hydrocarbons.

\section{INTRODUÇÃo}

A composição química do petróleo é bastante complexa devido à diversidade de compostos, majoritariamente hidrocarbonetos (Clark \& Brown 1977). O petróleo também é constituído por alcanos, cicloalcanos, alcenos, ácidos naftênicos, enxofre, nitrogênio, oxigênio e menores quantidades de vanádio, níquel, sódio, cálcio, cobre e urânio (Baker 1970). Sabe-se que moléculas de hidrocarbonetos pequenas, com baixa viscosidade, penetram com maior facilidade nos tecidos vegetais. Por outro lado, moléculas grandes apresentam maior viscosidade com conseqüente menor penetração nos tecidos vegetais (Baker 1970). Deste modo, o petróleo mais pesado apresenta

Artigo recebido em 10/2007. Aceito para publicação em 07/2008.

${ }^{1}$ Universidade Federal do Paraná, Centro Politécnico, Departamento de Botânica, Laboratório de Botânica Estrutural. 81531-990, C.P. 19031, Curitiba, PR, Brasil.

${ }^{2}$ Universidade Estadual de Maringá, UEM / DBI, Av. Colombo, 5790, Maringá, PR, 87020-900, Brasil.

${ }^{3}$ Autor para correspondência: cleusabona@ufpr.br 
menor toxicidade às plantas quando comparado ao petróleo mais leve (Dorn et al. 1998). A toxicidade do petróleo em relação às plantas pode ocorrer pelo contato direto ou absorção de algum composto, como foi registrado por Alkio et al. (2005). Estes autores detectaram fenantreno (composto presente no petróleo) no interior de Arabidopsis thaliana (L.) Heynh., e registraram redução no crescimento das raízes, diminuição no tamanho e número de folhas, deformação de tricomas, redução de pêlos radiciais e áreas necrosadas com morte celular.

Muitos outros fatores, ocasionados pela contaminação do ambiente por petróleo, podem interferir na toxicidade às plantas, como por exemplo, o tipo de solo, a estação do ano e o tempo que as plantas ficam expostas ao óleo (Baker 1970; Webb 1994; Lin \& Mendelssohn 1996; Pezeshki et al. 2000). O petróleo também altera as propriedades do solo, reduzindo a disponibilidade de água, de nutrientes e de oxigênio (Ranwell 1968; Cowell 1969; Baker 1970; De Jong 1980; Bossert \& Bartha 1985; Pezeshki et al. 2000; Martinez \& López 2001). Os compostos orgânicos polares, presentes nos hidrocarbonetos, são os prováveis responsáveis pela hidrorrepelência dos solos contaminados (Morley et al. 2005), limitando dessa maneira a absorção de água e de nutrientes pela planta. Características relacionadas à baixa disponibilidade de água, como maior ramificação da raiz, aumento da espessura da parede celular, maior área de espaços intercelulares, redução da área foliar, maior espessura dos tecidos foliares e maior densidade estomática foram registradas nas plantas em solo contaminado por petróleo e seus derivados (Adam \& Duncan 1999; Maranho et al. 2006). A baixa disponibilidade de nutrientes também está relacionada com a degradação dos hidrocarbonetos por microorganismos, pois durante esse processo os microorganismos competem com as plantas por nutrientes (De Jong 1980; Merkl et al. 2004). Desse modo, solos biorremediados com microorganismos devem apresentar teores reduzidos para muitos nutrientes. O petróleo também pode formar uma camada hidrofóbica na superfície do solo, restringindo o movimento de oxigênio, resultando em condições anaeróbicas para as raízes (Pezeshki et al. 2000). Mayer et al. (2005) sugerem que a maior ramificação das raízes pode estar relacionada com a falta de oxigênio e Larcher (2000), com a redução da disponibilidade de nutrientes.

Existem algumas formas de diminuir o impacto causado pela contaminação ambiental por petróleo e seus derivados, sendo uma delas a biorremediação. A biorremediação tem como objetivo retirar o contaminante do ambiente (solo, ar e água) por meio de organismos vivos (Pandey et al. 2000; Collin 2001). Há relatos acerca da diminuição da toxicidade do solo biorremediado sobre a germinação e desenvolvimento de plantas (Dorn \& Salanitro 2000), porém são raros os estudos que relatam a interferência do solo biorremediado em nível celular.

O presente trabalho foi desenvolvido com Mimosa pilulifera Benth. (Leguminosae) que coloniza terrenos úmidos, rasos ou muito alterados mecanicamente (Fowler \& Carpanezzi 1998). Essa espécie foi selecionada porque é nativa do local de estudo, que pertence à REPAR/PETROBRÁS, município de Araucária-Paraná. O estudo da estrutura da plântula poderia indicar o grau de estresse provocado pelo solo contaminado e pelo solo biorremediado. Diante disso, e considerandose a escassez de estudos anatômicos em plantas submetidas à contaminação por petróleo, o presente trabalho tem o objetivo de averiguar se há alterações na estrutura da raiz, hipocótilo, cotilédone e eofilo de $M$. pilulifera, sob a influência do solo contaminado por petróleo e do solo biorremediado.

\section{Material e Métodos}

O solo para montagem do experimento foi coletado na área da REPAR/PETROBRÁS que, no ano 2000, foi contaminada com quatro milhões de litros de petróleo. Em 2005, foi 
coletado solo contaminado com petróleo, solo biorremediado com fungos e bactérias hidrocarbonoclásticose solo não contaminado, em profundidade de zero a $30 \mathrm{~cm}$, em áreas próximas cerca de $5 \mathrm{~m}$ uma da outra. O solo contaminado foi coletado de uma área em que se retirou mecanicamente o excesso de petróleo e posteriormente foi isolada, não sofrendo intervenção. Nas áreas com solo biorremediado, o petróleo superficial e a vegetação morta foram removidos mecanicamente e o solo vem sendo biorremediado com microorganismos. $\mathrm{O}$ solo não contaminado foi coletado de uma área que não foi atingida pelo óleo e é recoberta pela vegetação nativa.

O solo coletado é caracterizado como gleisolo hidromórfico, que apresenta horizonte glei com caráter franco argilo siltoso (Carvalho et al. 2003). Informações mais detalhadas sobre as características físico-químicas e o teor de hidrocarbonetos totais do solo estão presentes na Tabela 1. O petróleo existente nesse solo foi caracterizado como do tipo cusiana com perfil parafínico, na faixa predominante de compostos de $\mathrm{C}_{10}$ a $\mathrm{C}_{14}$ (Petrobrás 2003) e é um petróleo pesado (comunicação pessoais).

O solo coletado foi peneirado, homogeneizado e distribuído em bandejas plásticas. As bandejas foram vedadas e levadas para casa de vegetação, com nebulização intermitente de 15 segundos a cada 30 minutos. As temperaturas máximas e mínimas foram registradas diariamente, tendo a média de $22^{\circ} \mathrm{C}$ (mínima $9,6^{\circ} \mathrm{C}$ e máxima $33,2^{\circ} \mathrm{C}$ ). O experimento foi analisado por um delineamento inteiramente casualizado, com três tratamentos e cinco repetições. Os tratamentos consistiram de solo contaminado por petróleo (SC), solobiorremediado (SB) e solo não contaminado (SNC) e em cada repetição foram semeadas 50 sementes, totalizando 750 sementes. As sementes de $M$. pilulifera foram fornecidas pela Embrapa Florestas, Município de Colombo-PR. Para a superação da dormência tegumentar, as sementes foram imersas em água, com temperatura inicial de $80^{\circ} \mathrm{C}$, durante 18 horas (Fowler \& Carpanezzi 1998), e em seguida semeadas. As plantas foram coletadas 30 dias
Tabela 1 - Atributos físico-químicos e teor de hidrocarbonetos totais do petróleo (TPH) do solo contaminado por petróleo (SC), solo biorremediado (SB) e solo não contaminado (SNC).

\begin{tabular}{|c|c|c|c|c|}
\hline & SC & SB & SNC \\
\hline \multirow{3}{*}{ Textura $(\%)$} & Areia & 24,8 & 19,7 & 26,1 \\
\hline & Silte & 50,0 & 45,0 & 52,5 \\
\hline & Argila & 25,2 & 35,2 & 21,3 \\
\hline \multicolumn{2}{|l|}{$\mathrm{pH}$} & 4,20 & 5,80 & 3,70 \\
\hline \multicolumn{2}{|c|}{ Alumínio $\left(\mathrm{cmolc} \mathrm{dm}^{-3}\right)$} & 4,10 & 0,00 & 6,00 \\
\hline \multicolumn{2}{|c|}{ Cálcio $\left(\mathrm{cmolc} \mathrm{dm}^{-3}\right)$} & 2,00 & 16,80 & 0,40 \\
\hline \multicolumn{2}{|c|}{ Magnésio $\left(\mathrm{cmolc} \mathrm{dm}^{-3}\right)$} & 1,50 & 1,80 & 0,20 \\
\hline \multicolumn{2}{|c|}{ Potássio $\left(\mathrm{cmolc} \mathrm{dm}^{-3}\right)$} & 0,24 & 0,21 & 0,10 \\
\hline \multicolumn{2}{|c|}{ Fósforo (mg dm $\left.{ }^{-3}\right)$} & 1,60 & 1,20 & 3,50 \\
\hline \multicolumn{2}{|c|}{ Carbono $\left(\mathrm{g} \mathrm{dm}^{-3}\right)$} & 26,9 & 19,6 & 23,8 \\
\hline \multicolumn{2}{|c|}{$\mathrm{TPH}\left(\mathrm{mg} \mathrm{kg}^{-1}\right)$} & 13.651 & 2.004 & 1.354 \\
\hline
\end{tabular}

após a semeadura, quando a maioria apresentava o eofilo completamente expandido. Foram analisadas duas plantas por bandeja, totalizando 10 plantas por tratamento.

As amostras foram fixadas parte em FAA 50 (Johansen 1940) e parte em fixador de Trump (McDowell \& Trump 1976). Raízes laterais, incluindo a região pilífera, foram clarificadas em solução de hipoclorito a $20 \%$, coradas com solução aquosa de azul de astra $1 \%$ (Kraus \& Arduin 1997) e montadas em gelatina glicerinada (Kraus \& Arduin 1997), entre lâmina e lamínula, para observação dos pêlos radiciais. Para análise anatômica foram processadas amostras da raiz principal (ápice radicial e a um centímetro do ápice), da região mediana do hipocótilo e do terço médio do cotilédone e eofilo.

As amostras foram processadas segundo técnicas usuais para inclusão em hidroxietilmetacrilato. As secções foram obtidas em micrótomo de rotação, distendidas em lâminas e coradas com azul de toluidina $0,05 \%, \mathrm{pH} 6,8$ (O'Brien et al. 1964), azul de astra 1\% e safranina 1\% (Kraus \& Arduin 1997) e, em seguida, montadas em resina. Também foram feitas secções para testes histoquímicos com lugol para detecção de amido (Johansen 1940), 
cloreto férrico para compostos fenólicos (Johansen 1940) e Sudan III para substâncias graxas (Sass 1951). A partir das lâminas permanentes foram mensurados: o raio do córtex e o diâmetro do cilindro vascular da raiz a $1 \mathrm{~cm}$ do ápice; o diâmetro do hipocótilo e a espessura dos cotilédones e eofilos. As mensurações foram feitas com auxílio de microscópio com ocular micrometrada.

Para análise da superfície foliar e avaliação da densidade estomática, foram preparadas amostras do terço médio do eofilo e processadas para Microscopia Eletrônica de Varredura (MEV). As amostras foram fixadas em FAA50 e desidratadas em série etílica. Em seguida, o material foi submetido ao método do ponto crítico no equipamento Balzers CPC 10. Após o ponto crítico, foi efetuada a metalização com ouro no equipamento Balzers Sputtering SCD 030. A análise e o registro eletromicrográfico do material foram efetuados no MEV Jeol JSM-6360LV. A contagem estomática foi feita em imagens com ampliação de 300x.

Os dados morfométricos obtidos foram analisados estatisticamente no programa MSTAT-C ${ }^{\circledR}$. Primeiramente verificou-se a variância dos tratamentos quanto à homogeneidade pelo teste de Bartlett. Posteriormente, as variáveis foram testadas pelo teste F. Quando as análises dos resultados demonstraram diferença estatística entre as médias dos tratamentos, as médias foram comparadas pelo teste de Tukey a um nível de significância de 5\%.

\section{Resultados e Discussão}

As raízes de $M$. pilulifera, em solo contaminado por petróleo, apresentaram visualmente maior densidade de pêlos em relação às raízes de solo biorremediado e de solo não contaminado (Fig. 1 a-c). A maior quantidade de pêlos radiciais de $M$. pilulifera pode indicar menor retenção de água no solo contaminado, uma vez que a função dos pêlos radiciais é aumentar a superfície de absorção da planta (Esau 1977). De acordo com Rosane (1954 apud Cutter 1986), a vantagem biológica dos pêlos radiciais é proporcionar maior superfície de contato com a água. A maior densidade de pêlos radiciais em $M$. pilulifera também pode estar relacionada à baixa disponibilidade de fósforo (Tab. 1). Segundo Ma et al. (2001), em Arabidopsis thaliana, a baixa disponibilidade de fósforo está relacionada à maior densidade de pêlos radiciais, que são importantes para a absorção de fósforo. Alkio et al. (2005), através de análises em microscopia de fluorescência, constataram a presença de fenantreno no interior das raízes de $A$. thaliana, sugerindo que a absorção do contaminante ocasionou deformação nos pêlos radiciais. Não foram observadas deformações nos pêlos radiciais de M. pilulifera, o que pode sugerir uma baixa toxicidade do solo contaminado e biorremediado.

Em secções longitudinais do ápice radicial de $M$. pilulifera observou-se que a região meristemática é menor nas plantas em solo contaminado por petróleo, o que sugere crescimento mais lento das raízes. Por outro lado, nas plantas que se desenvolveram em solo não contaminado e solo biorremediado, a região meristemática é mais extensa a partir do promeristema(Fig. 1 d-f). Achuba (2006) registrou redução no tamanho das células e na atividade mitótica no meristema apical radicial de Vigna unguiculata (L.) Walp. em solo com petróleo. $\mathrm{O}$ autor acredita que esse efeito foi causado por partículas tóxicas presentes no petróleo.

A raiz principal de $M$. pilulifera, cerca de $1 \mathrm{~cm}$ do ápice, apresenta epiderme unisseriada (Fig. 1 g-i). O córtex é formado por parênquima com reduzidos espaços intercelulares, endoderme com paredes delgadas (Fig. 1 g-i) e delicadas estrias de Caspary. O cilindro vascular é tetrarco e as células parenquimáticas do floema apresentam grãos de amido. Após 30 dias da semeadura, as plantas de todos os tratamentos já apresentavam início de instalação do câmbio na raiz principal. A epiderme da raiz é gradativamente eliminada e substituída pela periderme na região próxima ao colo. Nessa região o córtex parenquimático apresenta poucos espaços intercelulares, semelhantes a região a $1 \mathrm{~cm}$ do ápice, e cilindro vascular com crescimento 

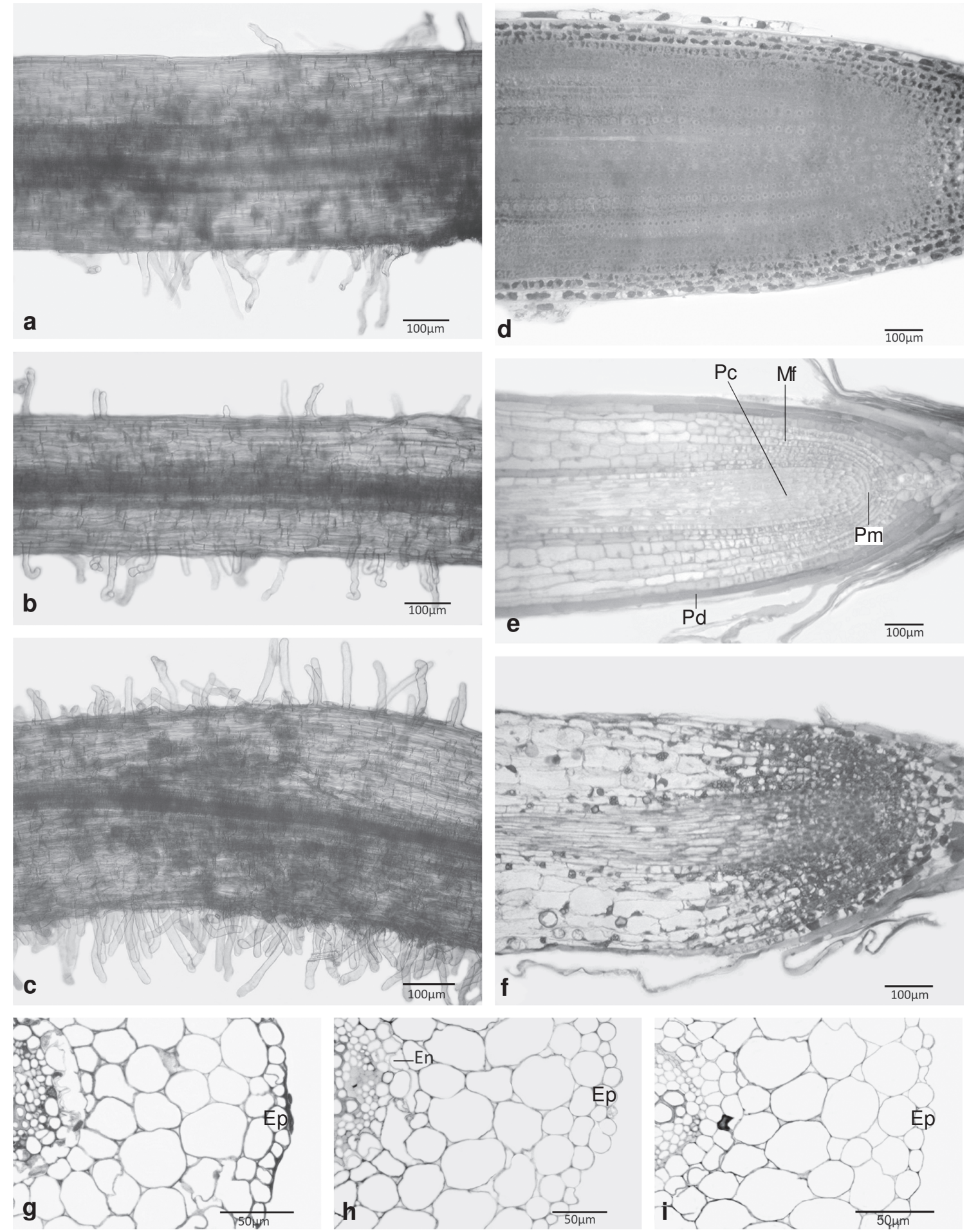

Figura 1 - Fotomicrografias da raiz de Mimosa pilulifera Benth., após 30 dias da semeadura. a-c. pêlos radiciais; df. ápices da raiz em secções longitudinais; g-i. detalhes do córtex das raízes em secções transversais. a, d, g. solo não contaminado; b, e, h. solo biorremediado. c, f, i. solo contaminado com petróleo. (En=endoderme; Ep=epiderme; $\mathrm{Mf}=$ meristema fundamental; $\mathrm{Pc}=$ procâmbio; $\mathrm{Pd}=$ protoderme; $\mathrm{Pm}=$ promeristema) 
secundário completamente desenvolvido, em todos os tratamentos.

A raiz de $M$. pilulifera a $1 \mathrm{~cm}$ do ápice, em solo contaminado por petróleo e em solo biorremediado, não apresentou alterações na disposição, conteúdo e formato das células da epiderme e do córtex (Fig. 1 g-i). O raio do córtex e o diâmetro do cilindro vascular das raízes também não foram alterados pela presença do petróleo no solo (p>0,05) (Fig. 2 a-b). De acordo com Larcher (2000) a formação de aerênquima nas raízes, pode estar relacionada a falta de oxigênio nos solos. Como não foi registrado aumento de espaços intercelulares no córtex da raiz de $M$. pilulifera, possivelmente o teor de oxigênio no solo contaminado não causou estresse para as plantas.

A redução da quantidade de compostos fenólicos foi observada em algumas espécies crescendo em solo com petróleo o que, provavelmente reduziu a quantidade de antioxidantes e interferiu na resistência da planta à contaminação (Malallah et al. 1998). Entretanto, em M. pilulifera, o estresse causado pelo solo contaminado e solo biorremediado da área da REPAR, aparentemente, não alterou a quantidade de compostos fenólicos nas plantas. Os diferentes efeitos da contaminação do ambiente nas plantas podem estar relacionados ao intervalo de tempo após a contaminação. Provavelmente, com o passar do tempo, o teor de TPH (teor de hidrocarbonetos totais de petróleo) do solo diminui devido à atividade microbiana (Merkl et al. 2004) e com conseqüente redução do estresse sobre as plantas.

Em secção transversal, o hipocótilo tem contorno sinuoso, a epiderme é unisseriada, finamente cuticularizada (Fig. 3 a-c) e apresenta tricomas tectores simples. O córtex é composto de colênquima nos ângulos e parênquima circundando todo o cilindro vascular (Fig. $3 \mathrm{a}$-c). O parênquima cortical é rico em células secretoras com compostos fenólicos, que aparentemente, não apresentaram alterações na concentração desses compostos entre os tratamentos (Fig. 3 a-c). Na região do hipocótilo, o câmbio está completamente instalado e há tecido secundário vascular diferenciado em todos os tratamentos (Fig. 3 a-c). A estrutura celular do hipocótilo de $M$. pilulifera não sofreu alteração no solo contaminado por petróleo nem no solo biorremediado (Fig. 3 a-c). O diâmetro do hipocótilo das plantas de M. pilulifera não apresentou diferença estatística entre os tratamentos (p>0,05) (Fig. 4 a). Em relação a raiz de $M$. pilulifera, o hipocótilo foi menos sensível ao solo contaminado, já que não apresentou alteração.

As células epidérmicas, tanto da face adaxial quanto da face abaxial do cotilédone de M. pilulifera, apresentam paredes anticlinais retas a levemente curvas (Fig. 3 d-e). Porém, as
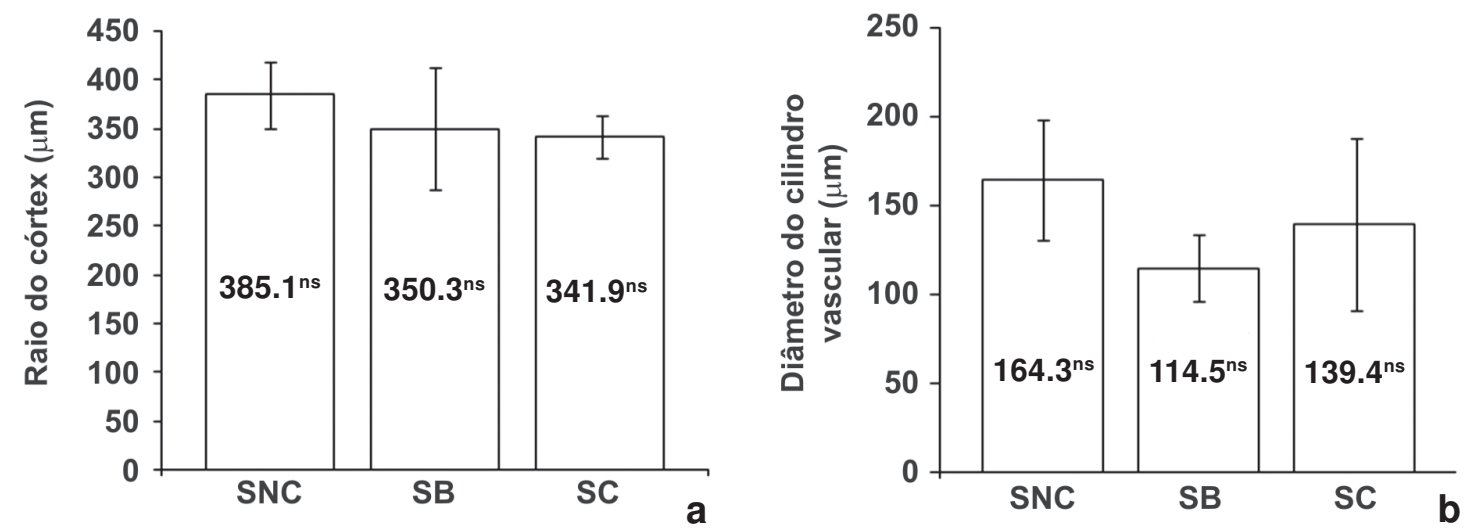

Figura 2 - Mensurações da raiz de Mimosa pilulifera Benth., após 30 dias da semeadura, em solo não contaminado (SNC), solo biorremediado (SB) e solo contaminado por petróleo (SC). Cada coluna representa a média de cinco repetições e as barras indicam o desvio padrão. ns = não significativo. 

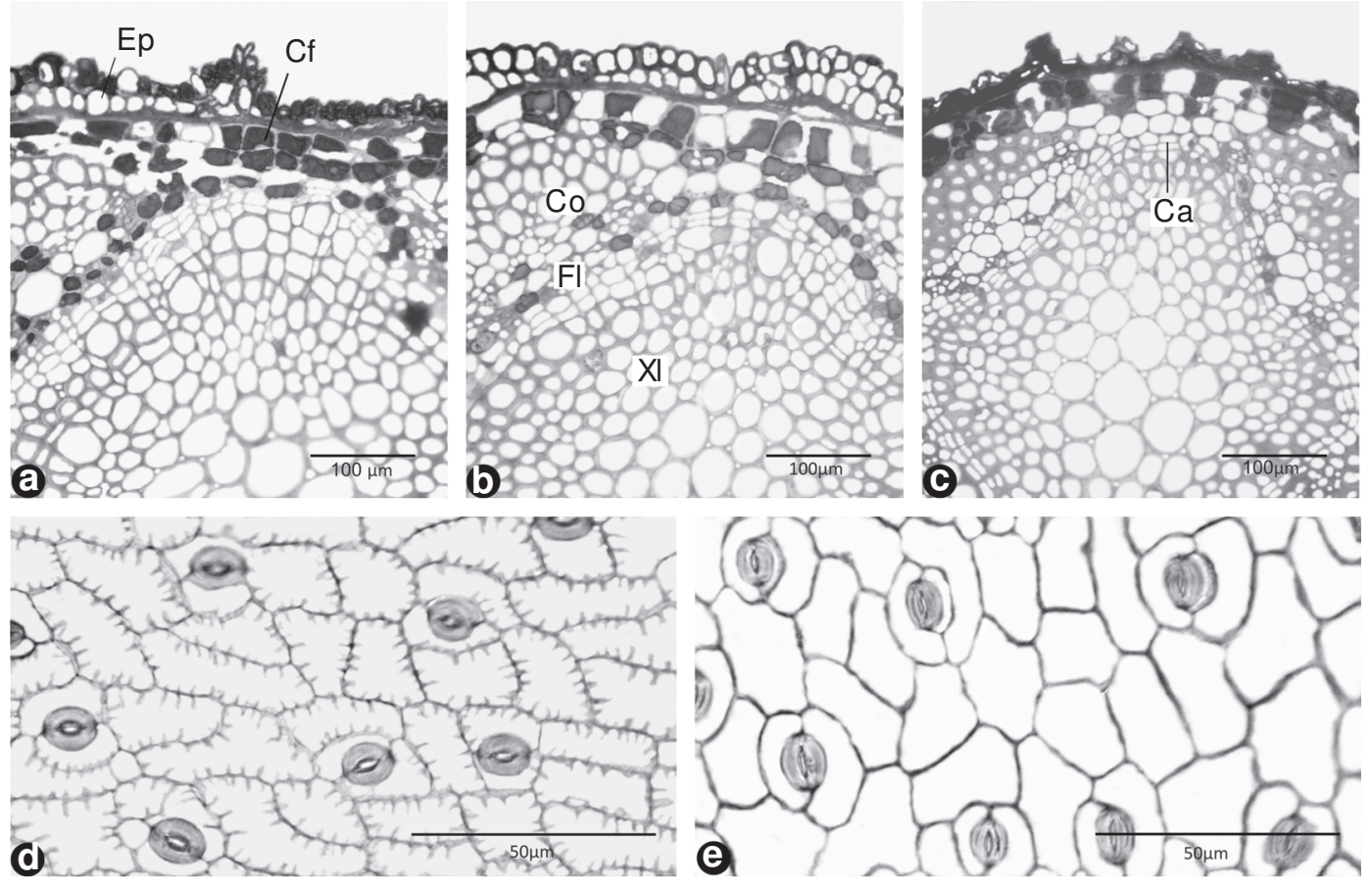

(6)

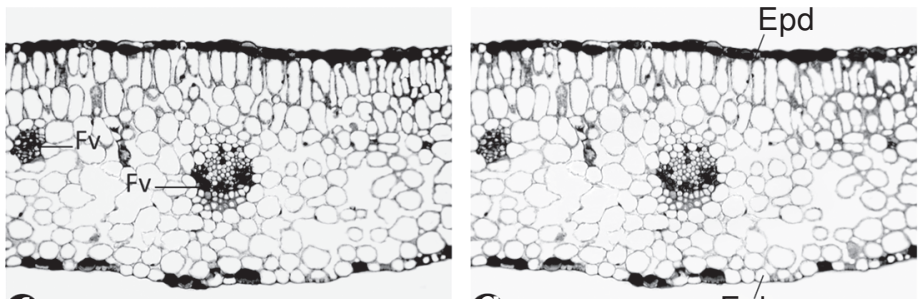

$\mathbf{0}$

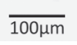

(9)

Epb $\overline{100 \mu \mathrm{m}}$

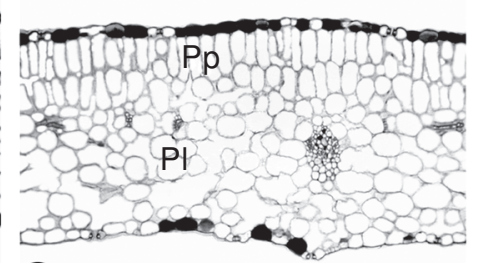

(b)

$\overline{100 \mu m}$

Figura 3 -Fotomicrografias do hipocótilo e cotilédone de Mimosa pilulifera Benth., após 30 dias da semeadura. a-c. hipocótilo em secção transversal em solo não contaminado (a), solo biorremediado (b) e em solo contaminado por petróleo (c); d-h. cotilédone; de. epiderme das faces adaxial (d) e abaxial (e), em vista frontal, de solo não contaminado; f-h. limbo em secção transversal de solo não contaminado (f), de solo biorremediado (g) e de solo contaminado por petróleo (h). (Ca=câmbio; $\mathrm{Cf}=$ compostos fenólicos; $\mathrm{Co}=$ colênquima; $\mathrm{Ep}=$ =piderme; Epd=epiderme da face adaxial; Epb=epiderme da face abaxial; $\mathrm{Fl}=\mathrm{floema} ; \mathrm{Fv}=$ feixe vascular; $\mathrm{Pl}=$ parênquima lacunoso; $\mathrm{Pp}=$ parênquima paliçádico; $\mathrm{Xl}=$ xilema).
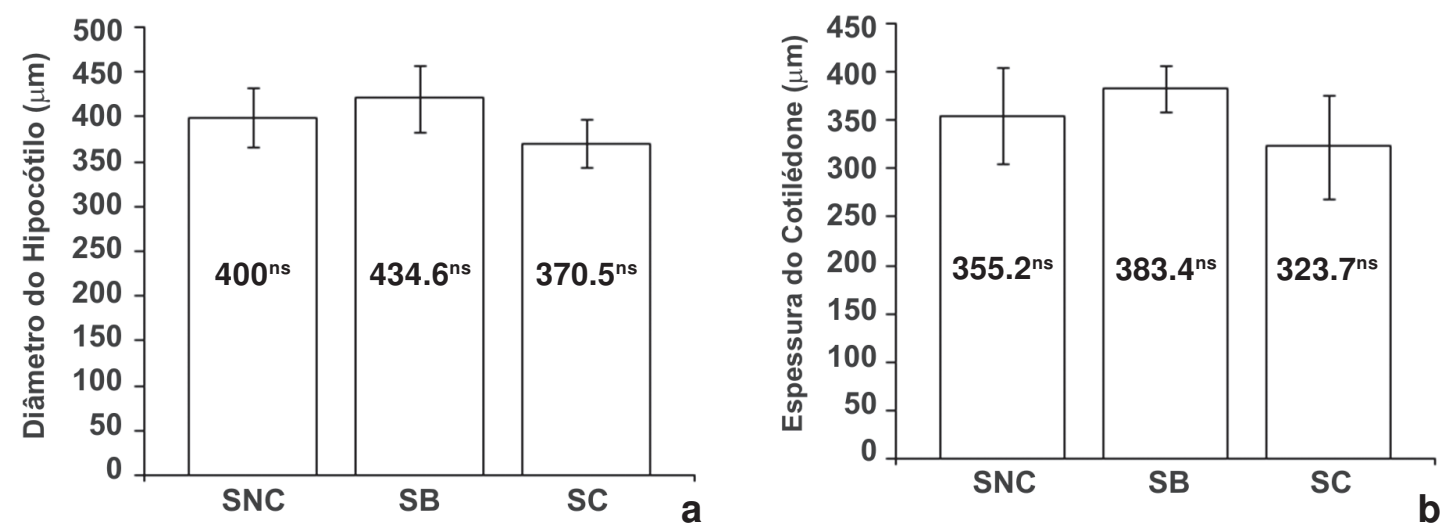

Figura 4 - Mensurações do hipocótilo e do cotilédone de Mimosa pilulifera Benth., após 30 dias da semeadura, em solo não contaminado (SNC), solo biorremediado (SB) e solo contaminado por petróleo (SC).Cada coluna representa a média de cinco repetições e as barras indicam o desvio padrão. ns = não significativo. 

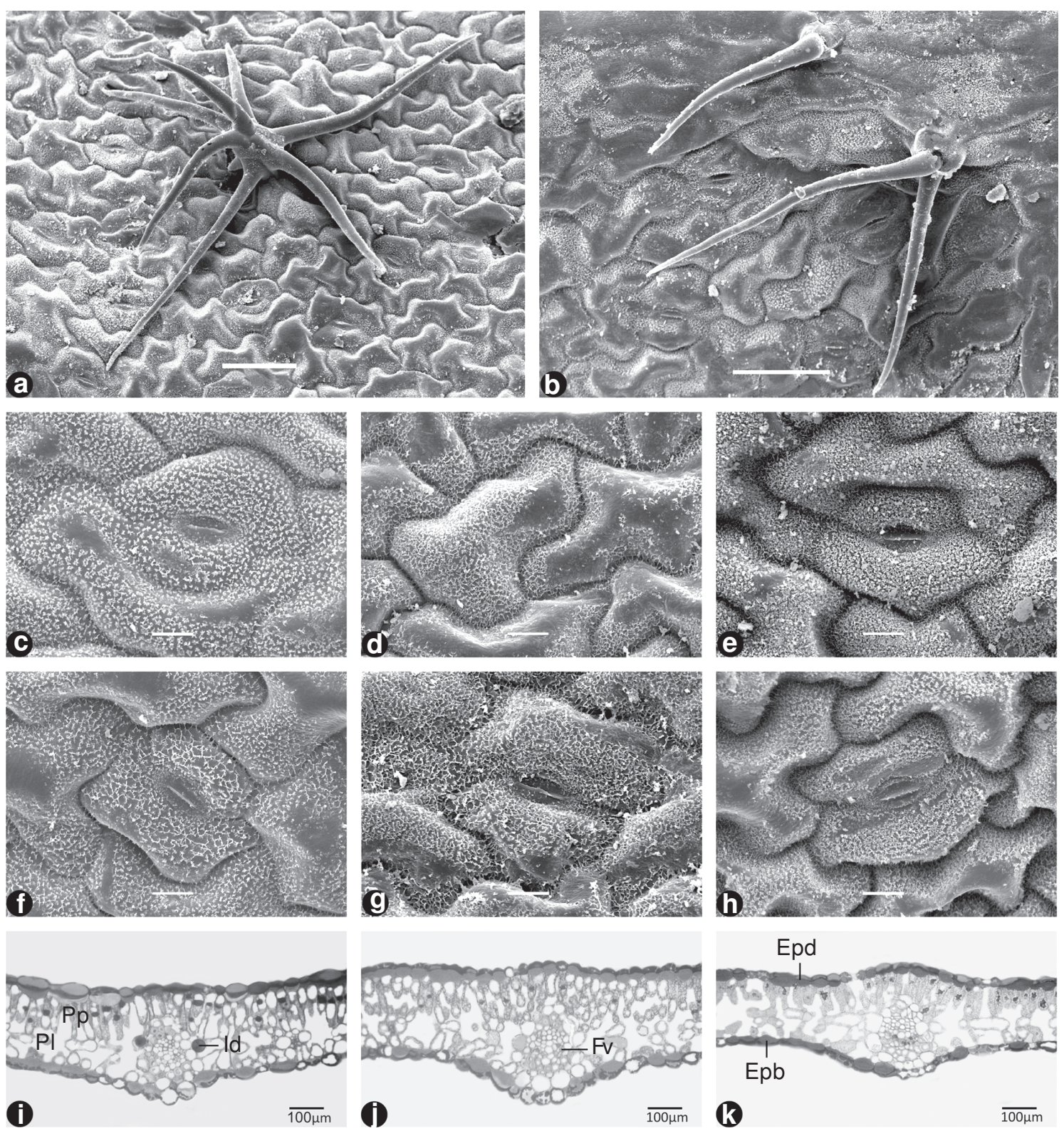

Figura 5 - Fotomicrografias do eofilo de Mimosa pilulifera Benth., após 30 dias da semeadura. a-b. tricomas dos eofilos em solo não contaminado; c-e. vista frontal da epiderme da face adaxial; $\mathrm{f}-\mathrm{h}$. vista frontal da epiderme da face abaxial; i-k. secções transversais. c, f, i. solo não contaminado; d, g, j. solo biorremediado; e, h, k. solo contaminado por petróleo. $(\mathrm{Epd}=$ =piderme da face adaxial; Epb=epiderme da face abaxial; $\mathrm{Fv}=$ feixe vascular; Id=idioblasto; $\mathrm{Pl}=$ parênquima lacunoso; $\mathrm{Pp}=$ parênquima paliçádico).

células epidérmicas da face adaxial apresentam projeções nas paredes anticlinais. O cotilédone é anfiestomático com estômatos paracíticos (Fig. 3 d-e). A região da nervura central, em vista transversal, é plana na face adaxial e ligeiramente saliente na face abaxial. A epiderme é unisseriada, com conteúdo mucilaginoso abundante e cutícula lisa e delgada. O mesofilo apresenta duas camadas de células de parênquima paliçádico e seis a sete camadas de parênquima lacunoso (Fig. $3 \mathrm{f}$-h), onde ocorre grande quantidade de grãos de amido e idioblastos lipídicos. A vascularização do cotilédone é feita pela nervura central, que possui um único feixe vascular de maior porte, e duas nervuras laterais, cada uma com um feixe de pequeno 

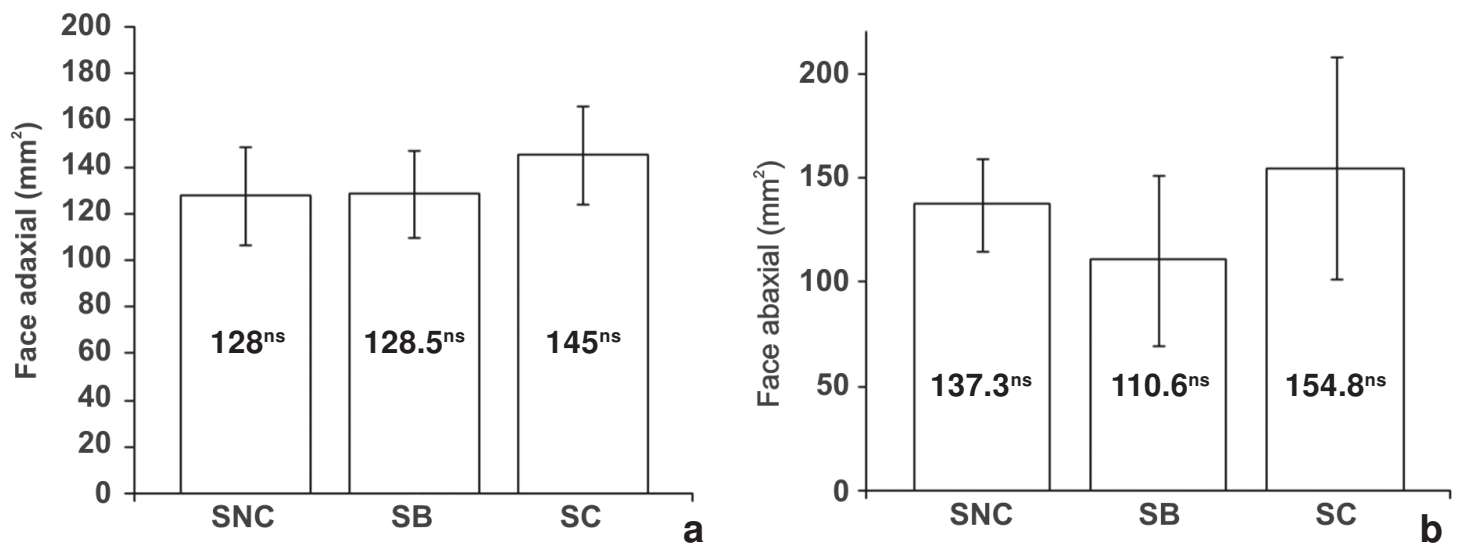

Figura 6 - Densidade estomática do eofilo de Mimosa pilulifera Benth., após 30 dias da semeadura, em solo não contaminado (SNC), solo biorremediado (SB) e solo contaminado por petróleo (SC), das faces adaxial (a) e abaxial (b). Cada coluna representa a média de cinco repetições e as barras indicam o desvio padrão. ns = não significativo.

porte. Não foram registradas alterações na estrutura dos cotilédones nas plantas dos diferentes tratamentos (Fig. 3 d-h), e a espessura dos cotilédones também não foi alterada pelo solo contaminado nem pelo solo biorremediado ( $>00,05)$ (Fig. 4 b).

Os eofilos de M. pilulifera apresentam tricomas pluricelulares ramificados ou não (Fig. 5 a-b) e estômatos paracíticos em ambas as faces (Fig. 5 c, e-f). A presença de tricomas estrelados, em folhas adultas de M. pilulifera, é citada por Cabrera \& Zardini (1978). A estrutura da cera epicuticular e dos tricomas foi visualmente semelhante entre os tratamentos.

O eofilo de M. pilulifera possui epiderme unisseriada, cuticularizada, com células que apresentam conteúdo mucilaginoso, em ambas as faces (Fig. 5 i-k). A espessura da cutícula foi semelhante entre os tratamentos (Fig. 5 ik). O mesofilo é dorsiventral, composto de duas a três camadas de células, sendo uma camada de parênquima paliçádico e uma a duas de parênquima lacunoso (Fig. 5 i-k). O eofilo apresenta pequena curvatura na face adaxial, sobre a nervura central, e uma proeminência na face abaxial. O sistema vascular é constituído por um feixe colateral maior na nervura central e feixes colaterais menores no restante do limbo. No eofilo também ocorrem idioblastos lipídicos (Fig. 5 i).
A estrutura celular dos eofilos (Fig. 5 c-k) e a densidade estomática, tanto da face abaxial quanto da face adaxial de M. pilulifera, não foram alteradas em solo contaminado nem em solo biorremediado ( $p>0,05$ ) (Fig. 6 a-b). A espessura dos eofilos de $M$. pilulifera foi $42,44 \%$ menor em solo contaminado por petróleo, quando comparada com as plantas em solo não contaminado $(\mathrm{p}<0,05)$ (Fig. 7). A espessura dos eofilos das plantas em solo biorremediado foi estatisticamente semelhante ao tratamento com solo não contaminado ( $p>0,05$ ) (Fig. 7). A menor espessura do primeiro eofilo de $M$. pilulifera, em solo contaminado por petróleo, se deve ao menor desenvolvimento que ocorreu na parte aérea destas plantas.

Como não foram detectadas alterações na morfologia das células, tricomas e ceras epicuticulares de M. pilulifera, é provável que o nível de toxicidade do solo contaminado por petróleo seja baixo para essa espécie. Alkio et al. (2005) detectaram deformações nos tricomas e lesões nas folhas de A. thaliana, provocadas pela absorção do fenantreno na planta. Devido a ausência de alterações na superfície epidérmica do eofilo de $M$. pilulifera, acredita-se que o solo contaminado 5 anos antes do experimento, não apresentava mais compostos voláteis presentes no petróleo. Folhas adultas de Podocarpus lambertii 


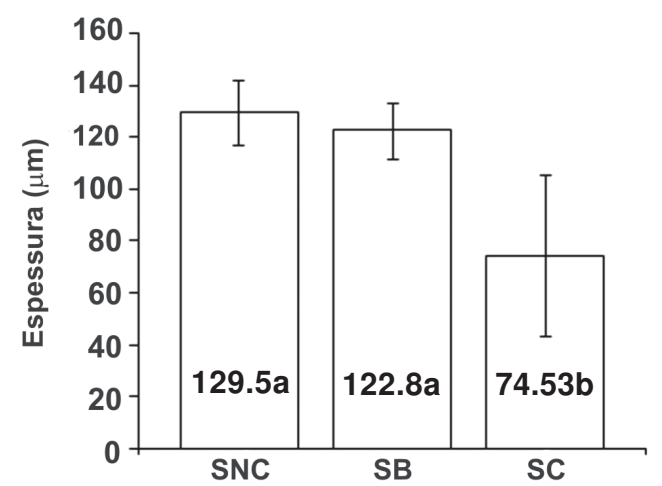

Figura 7 - Espessura do eofilo de Mimosa pilulifera Benth., após 30 dias da semeadura, em solo não contaminado (SNC), solo biorremediado (SB) e solo contaminado por petróleo (SC). Cada coluna representa a média de cinco repetições e as barras indicam o desvio padrão. As médias seguidas da mesma letra não são significativamente diferentes baseadas pelo teste de Tukey $(\mathrm{p}<0.05)$.

Klotzsch ex Endl., expostas à contaminação recente do solo por petróleo, sofreram aumento na espessura do limbo devido ao aumento no tamanho e número de células do parênquima, além de maior índice estomático (Maranho et al. 2006). Segundo os autores referidos, essas alterações ocorrem devido a pouca disponibilidade de água no solo. Em $M$. pilulifera, não ocorrerem alterações marcantes devido ao longo período de tempo após a contaminação, o que diminuiu o efeito fitotóxico do solo contaminado.

\section{Conclusão}

No sistema radicial, o solo contaminado com petróleo causou alteração na estrutura celular do meristema apical e provocou aumento no número de pêlos radiciais. A região meristemática foi mais curta nas raízes em solo contaminado evidenciando provavelmente menor número de células em mitose. A biorremediação do solo reduziu os efeitos do contaminante tanto no ápice quanto nos pêlos radiciais. A estrutura celular do córtex e do cilindro vascular não foi afetada pelo solo contaminado e nem pelo solo biorremediado.
Na parte aérea, o solo contaminado não causou alteração celular no hipocótilo e no cotilédone, porém a espessura do eofilo foi menor. O solo biorremedido não alterou a parte aérea das plantas.

\section{Agradecimentos}

Agradecemos à EMBRAPA pela doação das sementes, à PETROBRÁS pelo financiamento e fornecimento do solo e ao Centro de Microscopia Eletrônica da UFPR pelo uso dos laboratórios e equipamentos.

\section{REFERÊNCIAS BibLIOGRÁFICAS}

Achuba, F. I. 2006. The effect of sublethal concentrations of crude oil on the growth and metabolism of Cowpea (Vigna unguiculata) seedlings. The Environmentalist 26: 17-20.

Adam, G. \& Duncan, H. J. 1999. Effect of diesel fuel on growth of selected plant species. Environmental Geochemistry and Health 21: 353-357.

Alkio, M.; Tabuchi, T. M.; Wang, X. \& ColónCarmona, A. 2005. Stress responses to polycyclic aromatic hydrocarbons in Arabidopsis include growth inhibition and hypersensitive response-like symptoms. Journal of Experimental Botany 56(421): 2983-2994.

Baker, J. M. 1970. The effects of oils on plants. Environmental Pollution 1(1): 27-44.

Bossert, J. \& Bartha, R. 1985. Plant growth in soils with a history of oily sludge disposal. Soil Science 140(1): 75-77.

Cabrera, A. L. \& Zardini, E. M. 1978. Manual de la Flora de los Alrededores de Buenos Aires. ACME, Buenos Aires, 755p.

Carvalho, F. J. P. C.; Castro, R. A. C.; Abdanur, A.; Krenczynki, M. C.; Teixeira, S. C. \& Coneglian, D. 2003. Relatório sobre o monitoramento do solo contaminado. Repar/SMS.

Clark Jr., R. C. \& Brown, D. N. 1977. Petroleum properties and analyses in biotic and abiotic systems. In: Malis, D. C. 
Effects of petroleum on Artic and Subartic environments in organisms. 1 Nature and fate of petroleum. Academic Press, New York, 89p.

Collin, P. H. 2001. Dictionary of ecology and the environment. London: Peter Collin Publishing. 560p.

Cowell, E. B. 1969. The effects of oil pollution on salt-marsh communities in pembrokeshire and cornwall. Journal of Applied Ecology 6(2): 133-142.

Cutter, E. 1986. Anatomia vegetal: Parte I Células e tecidos. 2 ed. Roca, São Paulo, 304p.

De Jong, E. 1980. The effect of a crude oil spill on cereals. Environmental Pollution 22: 187-196.

Dorn, P. B. \& Salanitro, J. P. 2000. Temporal ecological assessment of oil contamined soils before and after bioremediation. Chemosphere 40: 419-426.

Dorn, P. B.; Vipond, T. E.; Salanitro, J. P. \& Wisniewski, H. L. 1998. Assessment of the acute toxicity of crude oils in soils using earthworms, microtox and plants. Chemosphere 35: 845-860.

Esau, K. 1977. Anatomy of seed plants. 2 ed. John Willey and Sons, New York, 550p.

Fowler, J. A. P. \& Carpanezzi, A. A. 1998. Tratamento para superação da dormência de Mimosa pilulifera Bentham. Comunicado Técnico 30: 1-3.

Johansen, D. A. 1940. Plant Microtechnique. McGraw-Hill Book Co., New York, 450p.

Kraus, E. J. \& Arduin, M. 1997. Manual básico de métodos em morfologia vegetal. Edur, Rio de Janeiro, 198p.

Larcher, W. 2000. Ecofisiologia vegetal. RiMa, São Carlos, 335p.

Lin, Q. \& Mendelssohn, I. A. 1996. A comparative investigation of the effects of South Louisiana crude oil on the vegetation of fresh, brackish, and salt marshes. Marine Pollution Bulletin 32(2): 202-209.

Ma, Z.; Bielenberg, D. G.; Brown, K. M. \& Lynch, J. P. 2001. Regulation of root hair density by phosphorus availability in
Arabidopsis thaliana. Plant, Cell and Environmentalist 24: 459-467.

Malallah, G.; Afzal, M.; Kurian, M.; Gulshan, S. \& Dhami, M. S. I. 1998. Impact of oil pollution on some desert plants. Environment International 24(8): 919-924.

Maranho, L. T.; Galvão, F.; Preussler, K. H.; Muñiz, G. \& Kuniyoshi, Y. S. 2006. Efeitos da poluição por petróleo na estrutura da folha de Podocarpus lambertii KLotzsch ex Endll., Podocarpaceae. Acta Botanica Brasilica 20(3): 615-624.

Martinez, V. E. \& López, M. F. 2001. Efecto de hidrocarborus em lãs propriedades físicas y químicas de suelo argiloso. Terra 19(1): 9-16.

Mayer, J. L. S.; Bona, C.; Santos, G. O. \& Koehler, H. S. 2005. Impacto do solo contaminado com petróleo no crescimento e desenvolvimento de Campomanesia xanthocarpa O. Berg. (Myrtaceae). In: IV Simpósio Nacional e Congresso Latino-americano de Recuperação de Áreas Degradadas, Curitiba, Brasil. Pp. 299-305.

McDowell, E. M. \& Trump, B. 1976. Histological fixatives for diagnostic light and electron microscopy. Archives of Pathology \& Laboratory Medicine 100: 405-414.

Merkl, N.; Schultze-Kraft, R. \& Infante, C. 2004. Phytoremediation in tropics- the effect of crude oil on the growth on tropical plants. Biorremediation Journal 8(3-4): 177-184.

Morley, C. P.; Mainwaring, K. A.; Doerr, S. H.; Douglas, P.; Llewellyn, C. T. \& Deker, L. W. 2005. Organic Compounds at different dephts in a sand soil and their role in water repellency. Australian Journal of Soil Research 43(3): 239-249.

O'Brien, T.P.; Feder, N. \& McCully, M.E. 1964. Polychromatic staining of plant cell walls by toluidine blue O. Protoplasma 59 (2): 368-373.

Pandey, A.; Soccol, C. R. \& Mitchell, D. 2000. New development in solid state fermentation: I. bioprocesses and products. 
Process biochemistry, Vandoeuvre-lesNancy 35(10): 1153-1169.

Petrobrás. 2003. Caracterização físicoquímico preliminar do óleo derramado da REPAR em julho de 2000. Relatório Técnico, Petrobrás, Curitiba, Paraná, Brasil.

Pezeshki, S. R.; Hester, M. W.; Lin, Q. \& Nyman, J. A. 2000. The effects of oil spill and clean-up on dominant US Gulf coast marsh macrophytes: a review. Environmental Pollution 108 (2): 129-139.
Ranwell, D. S. 1968. Extent of demange to coastal habitats due to the torrey canyon incident', in: the biological effects of oil pollution in litoral communities. Field Studies Council. Pp. 39-47.

Sass, J. E. 1951. Botanical microtechnique. 2 ed. Iowa State College Press, Iowa, 228p.

Webb, J. W. 1994. Effects of oil on saltmarshes. In: Assessing. Effects, natural recovery, and progress in remediation reserach. Symp. Proc. Gulf of México and Caribbean oil spill in Coastal Ecosystems. Pp. 55-61. 